\title{
An Earth Observation-based Approach for the Assessment of the Environmental Impact of Refugee and IDP Camps
}

\author{
Michael Hagenlocher, Dirk Tiede, Lorenz Wendt and Stefan Lang \\ Z_GIS, University of Salzburg, Austria·michael.hagenlocher@sbg.ac.at
}

Short paper

\begin{abstract}
Natural resources play a vital role for the well-being of the population of refugee and internally displaced persons (IDP) camps. An assessment of the environmental impact of these camps is important to sustain available resources and mitigate possible conflicts with host communities due to uncontrolled exploitation of natural resources. This paper presents a multi-stage Earth observation-based approach to assess and monitor environmental changes in the surrounding of refugee/IDP camps, consisting of rapid overview analyses, detailed land cover change investigations, and an evaluation of the implications of observed environmental changes for human well-being and ecosystem integrity.
\end{abstract}

\section{Introduction}

The devastating crises in Afghanistan, the Central African Republic, Iraq, Somalia, South Sudan, Syria, Ukraine or Yemen, among many others, along with disasters caused by climate-related extreme events (hurricanes, flooding, etc.) have resulted in population displacement at an unprecedented rate. In 2014, the number of people forced to flee their homes exceeded 50 million for the first time since the Second World War (UNHCR 2014). These numbers include internally displaced persons (IDPs), refugees, and asylum-seekers, whereby IDPs account for two-thirds of the world's forcibly uprooted population.

Although there is an increasing trend of refugees living in individual and private accommodations, in most instances displaced populations end up making a living in camps when abandoning their homes to seek protection, food, and shelter at a safer place (UNHCR 2014). Living conditions in such camps are often characterized by limited availability of resources (e.g. construction materials, fuel for cooking, etc.), forcing the inhabitants to rely on available natural resources in the vicinity of the camps to sustain their living. Evidence has shown that for these reasons such camps often have significant impacts on the environment (e.g. HAGENLOCHER et al. 2012, KRANZ et al. 2015). Severe deforestation, desertification, land degradation, unsustainable groundwater extraction, and water pollution are impacts that can be observed in the surroundings of many camps, often within a radius of up to $15 \mathrm{~km}$. Aside from contributing to suffering and violence in these camps, the continued overuse and the uncontrolled exploitation of resources may lead to conflict with the host community, and cause severe damage to local ecosystems. Therefore, the assessment of the environmental impact of refugee/IDP camps is important to organize the use of natural resources in a sustainable manner and to prevent further conflict. 
Within the research project EO4HumEn (EO-based Services to Support Humanitarian Operations), multi-temporal satellite imagery is used to assess (i) population dynamics in such camps, (ii) groundwater availability, (iii) as well as pressures exerted on the environment by human activities, such as wood gathering, overgrazing, etc. This paper focuses on the third component of the project, and presents an Earth observation (EO)-based approach to assess and monitor environmental changes in the vicinity of such camps.

\section{Concept and Methodology}

Extending an initial concept proposed by HAGENLOCHER et al. (2012), we present a multistage strategy for the assessment of the environmental impacts of refugee and/or IDP settlements based on multi-temporal remote sensing data (figure 1).

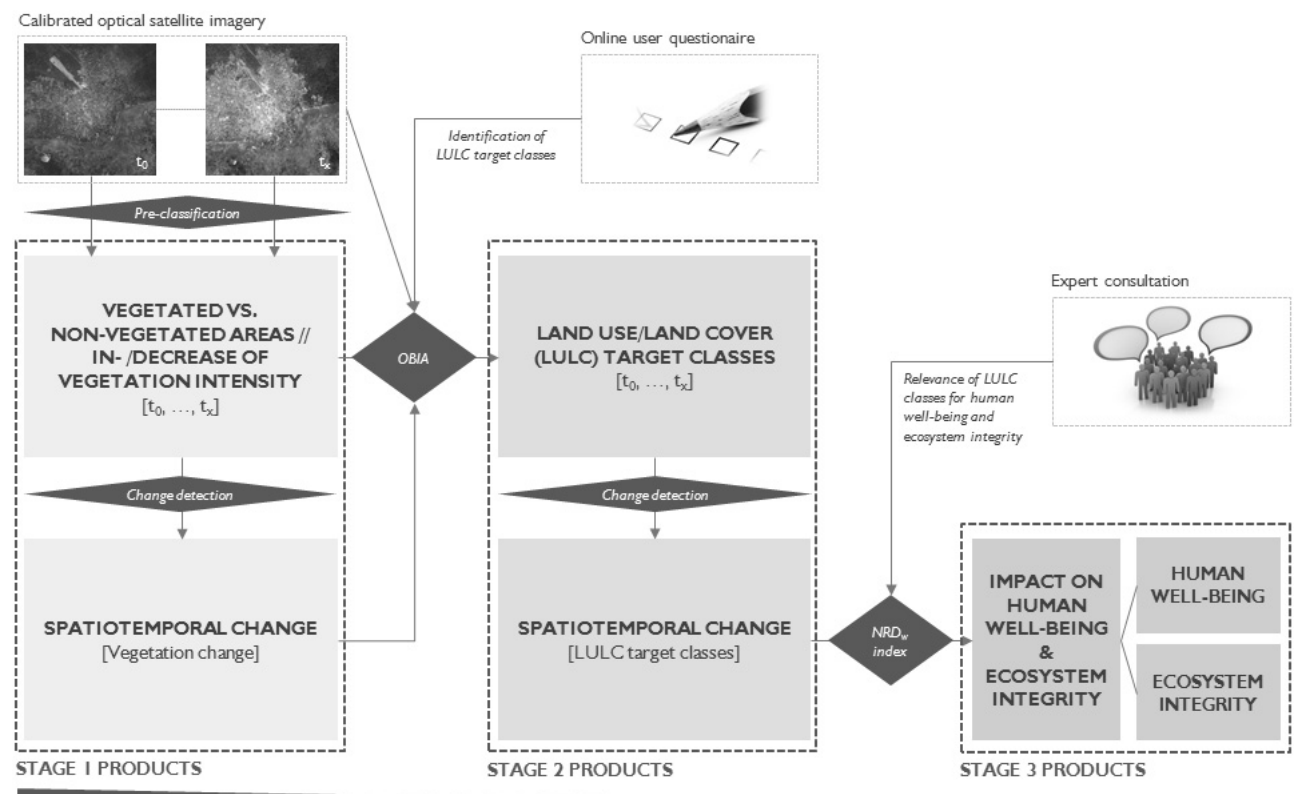

Degree of automation

Fig. 1: Multi-stage strategy for the assessment of the environmental impact of IDP/ refugee camps based on multi-temporal satellite imagery

Depending on the local context, and the needs of the humanitarian actors on the ground, different products (maps, statistics, and reports) are currently developed. Thereby, three broad categories of products that are based on a calibrated set of optical high resolution (HR) or very high resolution (VHR) satellite images can be distinguished. Thereby, the degree of automation decreases from stage 1 (+/- fully automatic) to stage 3 (semi-automated, user input required for weighting of indicators). The degree of automation relates reciprocally to the semantic enrichment of the land use/land cover (LULC) target classes. 
- Stage 1 products: based on time series of calibrated satellite imagery, an automatic preclassification is conducted. Calibration includes geometric registration and radiometric calibration into top-of-atmosphere reflectance, where surface reflectance calibrated data can be used if available. We use a feature space clustering approach implemented in the SIAM (Satellite Image Automatic Mapper; BARALDI et al. 2010) software environment, while the semantic information achieved is inferior to traditional land cover classes. Spatiotemporal changes in vegetation cover are assessed using an object-based postclassification change comparison (PCC) approach (TIEDE 2014).

- Stage 2 products: based on the outcomes of an online survey amongst possible users $(n=7)$ of the proposed products that was carried out within the EO4HumEn project, relevant LULC target classes were identified (e.g. water bodies, agricultural plots, single trees, forest areas, grassland, etc.). These are distinguished and mapped using the outcomes of the pre-classification, which are semantically enriched by expert rule-sets in an object-based image analysis (OBIA) environment. Further, the potential of fused optical and Synthetic Aperture Radar (SAR) data is currently evaluated in studies as discussed by BRAUN and HOCHSCHILD (this volume). Again, spatiotemporal changes are analysed using the PCC method.

- Stage 3 products: based on the Weighted Natural Resource Depletion $\left(\mathrm{NRD}_{\mathrm{w}}\right)$ index (HAGENLOCHER et al. 2012), these products enable users to identify and evaluate the impact of observed environmental changes on human well-being (i.e., food and livelihood security) and ecosystem integrity (i.e., state of ecosystems). The evaluation is based on an analysis of spatiotemporal changes of pre-defined LULC target classes, while taking into account their relative importance for human well-being and ecosystem integrity as identified by local experts.

\section{Preliminary Results}

Within the first phase of the EO4HumEn project, the environmental impact of three refugee camps was analysed: (i) Yida, South Sudan, (ii) Dagahaley, Kenya, and (iii) Minkaman, South Sudan. Thereby, the focus was primarily set on stage 1 and stage 2 products. Stage 3 products will be developed over the remainder of the project. Figure 2 exemplarily portrays a final stage 1 map product for the refugee camp in Yida.

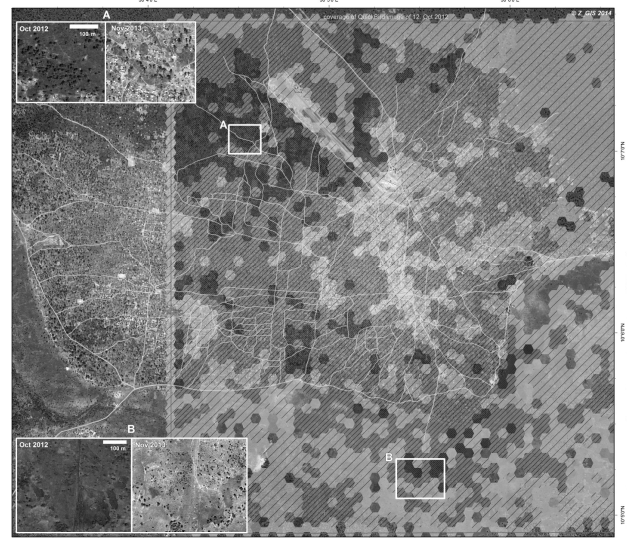

Fig. 2: Changes in vegetation cover from October 2012 to November 2013 in Yida, South Sudan using hexagons as the reporting unit.

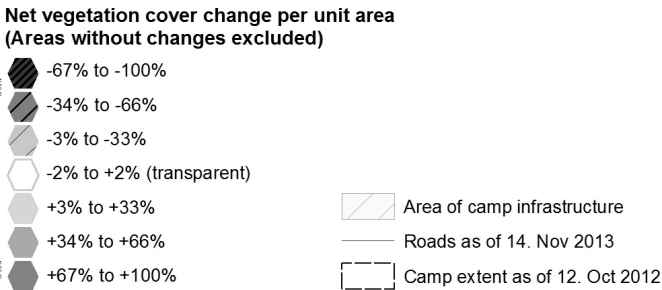


Spatiotemporal changes in vegetation cover from October 2012 (QuickBird) to November 2013 (WorldView-2) are displayed using hexagons as the unit of analysis, where shades of red indicate a decrease and shades of green an increase in vegetation cover. The fully automatic change analysis is restricted to the overlapping area of the two satellite images.

\section{Conclusions}

We present a multi-stage strategy for the EO-based assessment of the environmental impact of refugee or IDP settlements. Based on the respective needs of the humanitarian organizations in the field, different products can be provided, ranging from a rapid (i.e. automatic) assessment of vegetation change, over detailed LULC change investigations, to an evaluation of the implications of observed changes for human well-being and ecosystem integrity. A survey among possible users has revealed that the assessment and monitoring of environmental changes is of utmost importance for humanitarian organizations to protect the environment, improve environmental sustainability, and ultimately contribute to mitigating conflict between displaced populations and their host communities.

\section{Acknowledgements}

The research has received funding from the Austrian Research Promotion Agency (FFG) under the Austrian Space Application Programme (ASAP) within the project EO4HumEn (contract no: 840081).

\section{References}

Baraldi, A., Durieux L., Simonetti, D., Conchedda, G., Holecz, F. \& Blonda P. (2010), Automatic spectral rule-based preliminary classification of radiometrically calibrated SPOT-4/-5/IRS, AVHRR/MSG, AATSR, IKONOS/QuickBird/OrbView/GeoEye and DMC/SPOT-1/-2 imagery - Part I: System design and implementation. IEEE Transactions on Geosciences and Remote Sensing, 48 (3), 1299-1325.

BRAUn, A \& HochSCHILD, V. (2015), Combining SAR and optical data for environmental assessments around refugee camps. In: GI_Forum 2015/1. Journal for Applied Geoinformatics. Wichmann Verlag, Berlin/Offenbach; ÖAW Verlag, Wien, 426-435.

HAgenlocher, M., LANG, S. \& TIEDE, D. (2012), Integrated assessment of the environmental impact of an IDP camp in Sudan based on very high resolution multi-temporal satellite imagery. Remote Sensing of Environment, 126, 27-3.

KranZ, O., SACHS, A. \& LANG, S. (2015), Assessment of environmental changes induced by internally displaced person (IDP) camps in the Darfur region, Sudan, based on multitemporal MODIS data. International Journal of Remote Sensing, 36 (1), 190-210.

TIEDE, D. (2014), A new geospatial overlay method for the analysis and visualization of spatial change patterns using object-oriented data modeling concepts. Cartography and Geographic Information Science, 41, 227-234.

UNHCR (2014), Global Trends 2013. http://www.unhcr.org/5399a14f9.html. 